\title{
Anthropometric Properties versus Physical Performance in Rugby Union Forwards and Backs - A Systematic Review
}

\author{
${ }^{1}$ Rahel Stoop ${ }^{*},{ }^{1,2,3}$ Erich Hohenauer, ${ }^{4}$ Alfred ML Rucker, ${ }^{1,2,3}$ Ron Clijsen \\ ${ }^{1}$ Department of Business Economics, Health and Social Care, Rehabilitation Research Laboratory, University of Applied \\ Sciences and Arts of Southern Switzerland, Landquart, Switzerland. ${ }^{2}$ THIM University of Applied Sciences, Landquart, \\ Switzerland. ${ }^{3}$ Department of Movement and Sport Sciences, Vrije Universiteit Brussel, Brussels, Belgium. \\ ${ }^{4}$ Department of Physiotherapy, Döpfer-Schulen, Regensburg, Germany.
}

\begin{abstract}
Background. Rugby union is a team sport with a high amount of physical contact during match play. The physical performance and anthropometric characteristics required, differ based on the playing position. Objectives. The objective of this systematic review was to relate anthropometric properties with physical performance parameters in Rugby union backs and forwards across different playing levels of Tier 1 nations. Methods. Two electronic searches were performed in MEDLINE on the PubMed and on BISp (German Federal Sports Science Institute) databases from August 2016 to July 2017. All experimental study types in English and German were assessed for eligibility. Inclusion criteria were 15-a-side senior male backs and forwards, with anthropometric and/or physical performance data. Results. In $n=7$ studies out of 12 selected, the elite forwards were significantly taller than the elite backs ( $p<0.05$ ). This accounted not for lower playing levels. Across all levels the forwards were significantly heavier than the backs. Significantly lower body fat percentages for the backs demonstrated $n=5$ out of 6 studies. Consequently, backs were more ectomorphic than forwards. Backs reached significantly lower sprint velocities over short distances and higher ones over longer distances ( 10 to $40 \mathrm{~m}$ ). Conclusion. Anthropometric parameters adapt to physical performance requested. In strength and endurance test situations heavier players may be underestimated postulating careful interpretation of those results to avoid misleading conclusion.
\end{abstract}

KEY WORDS: Anthropometric Properties, Body Composition, Physical Performance, Rugby Union, Somatotype.

\section{INTRODUCTION}

Rugby union is a contact team sport played outdoors on a grass field, one match lasts 80 minutes, interrupted by a 10 -minute half time break. One team consists of 15 players a-side, divided into two units, 8 forwards and 7 backs (1). Since 1995 when Rugby union became professional, the amount of physical contact during match play has increased (2). The forwards cope with $62 \%$ (3) to $68 \%$ (4) of all collisions during a match, indicating the need for a mesoendomorphic body composition to sustain these impacts (5). Consequently, physical demands and hence anthropometric characteristics differ between playing positions (6). Further, changes made in the year 2000 have led to a faster (7) and more attractive match play which has, in turn, influenced the requirements of each playing position over time (8). Thus, a tendency towards

*. Corresponding Author:

Rahel Stoop

E-mail: rahel.stoop@supsi.ch 
heavier and taller players with enhanced physical performance characteristics has occurred (9-11). Large body size strongly correlates with team $(12,13)$ and individual player success (12), high body mass and anaerobic cycle test performance with scrum force (14). Since new regulations on foreign player transfers were instated, promoting young talent has become more important (12). A lower percentage of body fat and faster sprint times over a distance of $15 \mathrm{~m}$ were the most meaningful predictors in 15 -year old rugby players for career success, indicating a correlation between anthropometric profile and physical performance parameters (15). Therefore, an appropriate monitoring of body composition is crucial to ensure the optimal development of a rugby specific somatotype (5).

Nicholas (1997) described in his review the differences in body height and mass, total body fat and lean body mass between first and second class players (1). Further, the author highlighted the importance to analyze the anthropometric and physiological performance in relation to positional physical demands (1). Other literature comparing playing levels concluded that fat free mass is the only significant predictor of level classification (16).

Therefore, the aim of this review was to describe and evaluate the anthropometric and match relevant physical performance outcomes between senior back and forward players of elite (professionals, national team and first division players), sub-elite (semi-professionals, second division, college players) and amateur level (nonprofessionals, non-licensed) of Tier 1 nations according to World Rugby.

\section{MATERIALS AND METHODS}

Search Strategy. This study was performed according to the PRISMA statement (17). From August 2016 until July 2017, the German Federal Sports Science Institutes' database (BISp) and the Medical Literature Analysis and Retrieval System Online (MEDLINE) were searched for articles. The non-MeSH proofed key word "Rugby union" was combined with the Boolean formula "AND" with "anthropometry" (MeSH), "physical activity" (MeSH), "physical performance" (non$\mathrm{MeSH}$ ), "body composition" (non-MeSH), "somatotype" (non-MeSH). Additional literature was found by the function "similar articles" on
MEDLINE and by screening the reference lists of the retrieved articles.

Study Selection and Data Extraction. Inclusion and exclusion criteria were set a priori. Clinical trials in English and German were included and used as sources of primary literature to describe and evaluate the anthropometric and match relevant physical performance outcomes between senior ( $\geq 18$ years old) male back and forward 15-a-side Rugby union players of elite, sub-elite and amateur level of Tier 1 nations (New Zealand, South Africa, England, Australia, France, Ireland, Wales, Argentina, Scotland, Italy). Two researchers (EH, RS) independently screened the titles and abstracts of the retrieved studies for their eligibility. Cases of disagreement were solved in a consensus meeting with a third researcher (RC). Data were extracted by the same procedure. The results were subdivided into 1) anthropometric parameters and somatotypes, 2) locomotive parameters and sprint performance during matches, 3 ) lower and upper body strength and power performance. The sequence of the description followed the professionalism in decreasing order. Playing positions were divided into two units, forwards and backs. Somewhere possible, the units were further sub-divided as follows: the props, hookers, second row, flankers and the number 8 were considered to be forwards, the scrum-half, fly-wing, right and left wings, inside and outside center and full-backs to be backs. A significance level of $p<0.05$ was accepted for the reported study results.

\section{RESULTS}

In total, $\mathrm{n}=29$ studies met the inclusion criteria (see Figure 1). The studies showed a wide heterogeneity for the outcome parameters, precluding a general analysis:

1) body fat composition was reported as total body fat (\%) (16, 18-23), lean body mass $(\mathrm{kg})$ and total body fat mass ( $\mathrm{kg}$ ) (18)

2) running performance comprises locomotive parameters during matches $(3,24-26)$, agility assessments including the T-Test ( $s$ ) (27), Illinois Agility-Test $(s)(27)$ and the Agility Run-Test (s) (28), endurance assessments as the Intermittent Progressive Running Test (IPRT) $(\mathrm{m} / \mathrm{s})$ to assess the maximal aerobic velocity (21), the $20 \mathrm{~m}$-Multistage Fitness Test (20 m-MFT) (level) $(27,28)$, the 30-15 
Intermittent Fitness Test (30-15 IFT) $(\mathrm{m} / \mathrm{s})$ (29) and the Yo-Yo Intermittent Recovery Test level 1 (YYIRT) ( $m$ ) (29)

3) lower body strength was tested via the one repetition maximum (1RM) ( $\mathrm{kg}$ ) of box squats $(22,30)$ lower body force production by means of peak power (PPO) counter-movement jump performance (CMJ) (W/kg) (31), 70-kg- squat jump (SJ) PPO (W/kg) (22), standing arm reach up $C M J(\mathrm{~cm})$ (14), vertical jump (VJ) height $(\mathrm{cm})(2,28)$, upper body strength by the IRM bench press performance $(\mathrm{kg})(22,30)$ or maximal number of push-ups (No of repetitions) $(2,28)$ performed, upper body force production by using the $50-\mathrm{kg}$ bench throw PPO (W/kg) $(2,28)$.

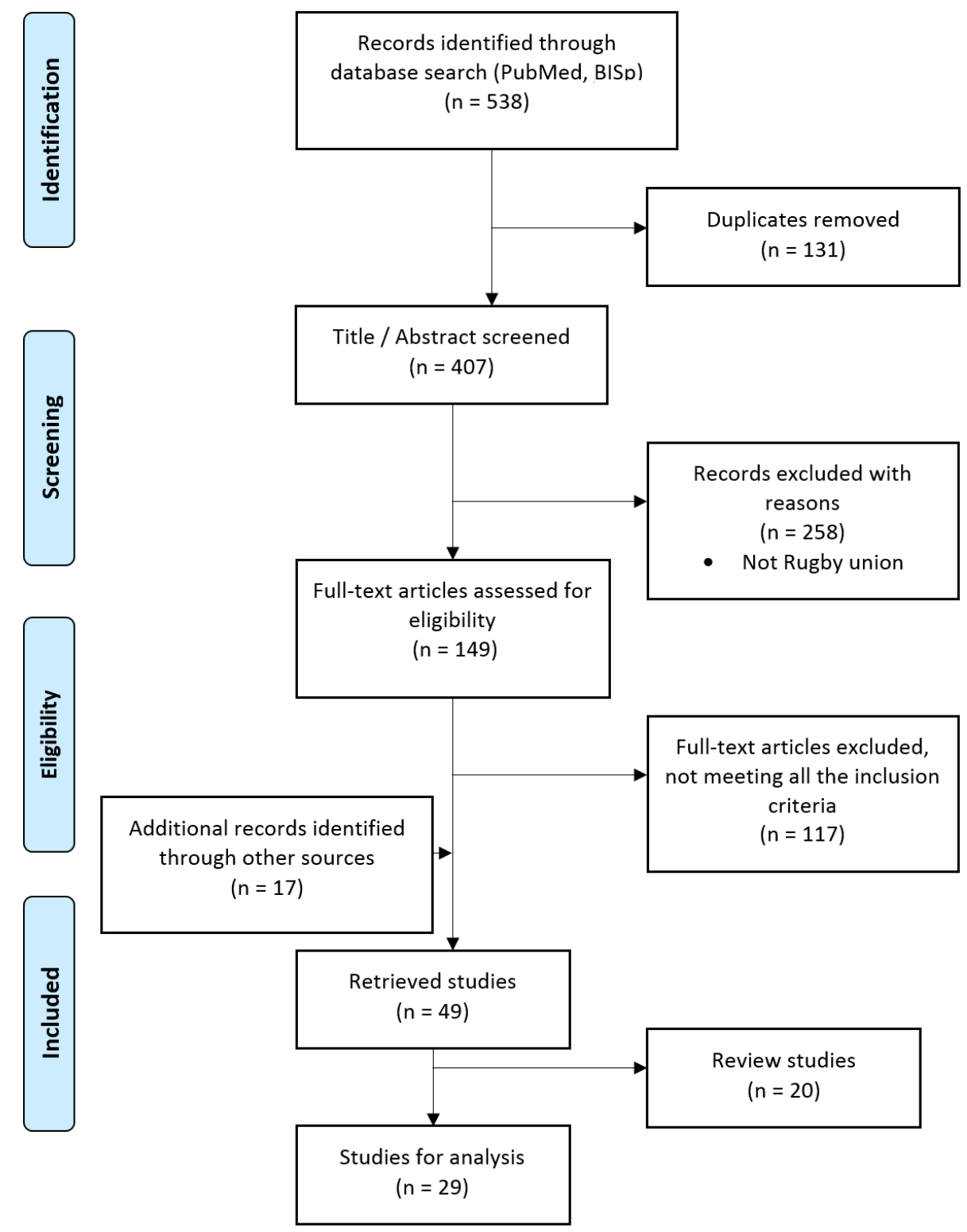

Figure 1. Flow chart of the study selection process.

Anthropometric Parameters and Somatotype. The $n=12$ studies focusing on height of forwards and backs involved all levels (see Table 1) (16, 19-23, 27, 28, 32-35). Data showed significantly taller elite forwards than backs in $n=7$ studies $(16,19,22,23,28,33$, 
34). In sub-elite and amateur players, the height difference between forwards and backs was non-significant (27). Two of the selected studies $(16,21)$ and $n=1$ additional study (2) compared the heights within the units. In the elite forwards, the locks were the tallest players and the hookers the shortest (16). Within the elite and second division backs, the outside backs were taller than the half scrums (16). Within the sub-elite forwards the locks were significantly taller than the props, hookers and loose forwards $(p=0.001)(2)$. Within the backs, the midfield and outside backs were significantly taller than the inside backs $(\mathrm{p}=$ 0.001) (2). Lacome et al. (2014) mentioned non-significant results for the within unit comparison (21).

A total of $n=13$ studies displayed body mass data for both units, out of them $n=9$ showed significantly heavier forwards (16, 19-23, 28, 33, 34). The results revealed that the lower the level, the lighter both units were. Of the elite forwards, the props were significantly the heaviest sub-group ( $\mathrm{p}<$ 0.05). All back sub-groups were significantly lighter than each forward sub-group ( $\mathrm{p}<$ $0.05)(16,21)$. In sub-elite forwards, the props were the heaviest sub-group, the hookers the lightest $(p=0.006)(2)$. Of the backs, the midfield players were heavier than the inside backs ( $p=0.001)(2)$.

Body fat percentage was reported in $n=6$ studies, the results covered all levels, with lower fat percentages for backs $(16,18,19,21,23,30)$. Out of these studies, $\mathrm{n}=5$ mentioned a significant difference $(\mathrm{p}<0.05)(16,18,19,23$, $30), \mathrm{n}=1$ mentioned non-significant results (21). Within the backs' group, on elite level, the outside backs and the half scrums were leaner than the inside backs (16). Within the elite and sub-elite forwards' group, the front row / props had the highest fat percentage, the third row the lowest (see Table 1) (16). On amateur level, Bell (1979) showed a significantly lower total body fat percentage for the backs and consequently a significantly higher lean body mass for the backs $(87.83 \pm 3.9 \mathrm{~kg},[\mathrm{n}=28])$ versus forwards $(80.51$ $\pm 3.76 \mathrm{~kg},[\mathrm{n}=28]),(\mathrm{p}<0.001)(18)$.

The $n=3$ studies reporting on somatotypes presented a higher degree of mesoendomorphy than ectomorphy for elite and sub-elites forwards $(14,28,36)$. The same composition was mentioned for elite and subelite backs, whereas here the mesomorphic and endomorphic portion was lower compared to the forwards, with the ectomorphy being higher $(28,36)$. A secular trend for the forwards was seen in the study of Holway and Garavaglia (2009) compared to the earlier studies (see Figure 2) (36).

Physical Performance. For the total distance covered during a match, data from elite level players was available. Out of the $n=7$ included studies, $\mathrm{n}=5$ reported significantly higher total match distance for backs than forwards $(p<0.05)(37-41)$. From $n=2$ studies no details were available $(3,25)$. The values of the backs varied between 5693 to $6544 \mathrm{~m}$, for the forwards between 4757 to $6038 \mathrm{~m}(3,24$, $25,37,38,40,41$ ).

Locomotive parameters were evaluated in $\mathrm{n}=$ 5 studies, investigating elite players, speed ranges are described somewhere else $(3,25,26$, $39,40)$.

The backs covered significantly fewer distance standing $(293 \pm 63 \mathrm{~m},[\mathrm{n}=15])$, and more distance walking $(2351 \pm 287 \mathrm{~m}[\mathrm{n}=$ 15]) than the forwards $(354 \pm 50 \mathrm{~m}[\mathrm{n}=14]$, $1928 \pm 234 \mathrm{~m}[\mathrm{n}=14])$, respectively ( $\mathrm{p}<$ $0.05)$ (24). These results are in line with Deutsch et al. (2007) and Jones et al. (2015) $(26,42)$. For low-speed running (25) or jogging $(24,40)$, forwards and backs covered equal distances, $(\mathrm{p}<0.05)$. Conversely, $\mathrm{n}=1$ study reported a significant difference for forwards' jogging time compared to the backs $(p<0.0125)(26)$. Significantly longer sprint times for backs than for the forwards were reported $(26,40)$.

A total of $n=6$ studies measured sprint time for distances between $2 \mathrm{~m}$ and $60 \mathrm{~m}$, comparing forwards and backs at the elite and sub-elite level $(27,28,30,32,35,43)$. A total of $n=4$ studies described sprint velocity (30, $32,35,43)$ and $\mathrm{n}=1$ reported sprint momentum results (28). Overall, the backs were faster than the forwards (see Table 2), the elites faster than the lower categories. Significantly higher sprint velocities achieved by the backs were reported for distances of $10 \mathrm{~m}$ to $40 \mathrm{~m}$, respectively (see Table 2) (30). 


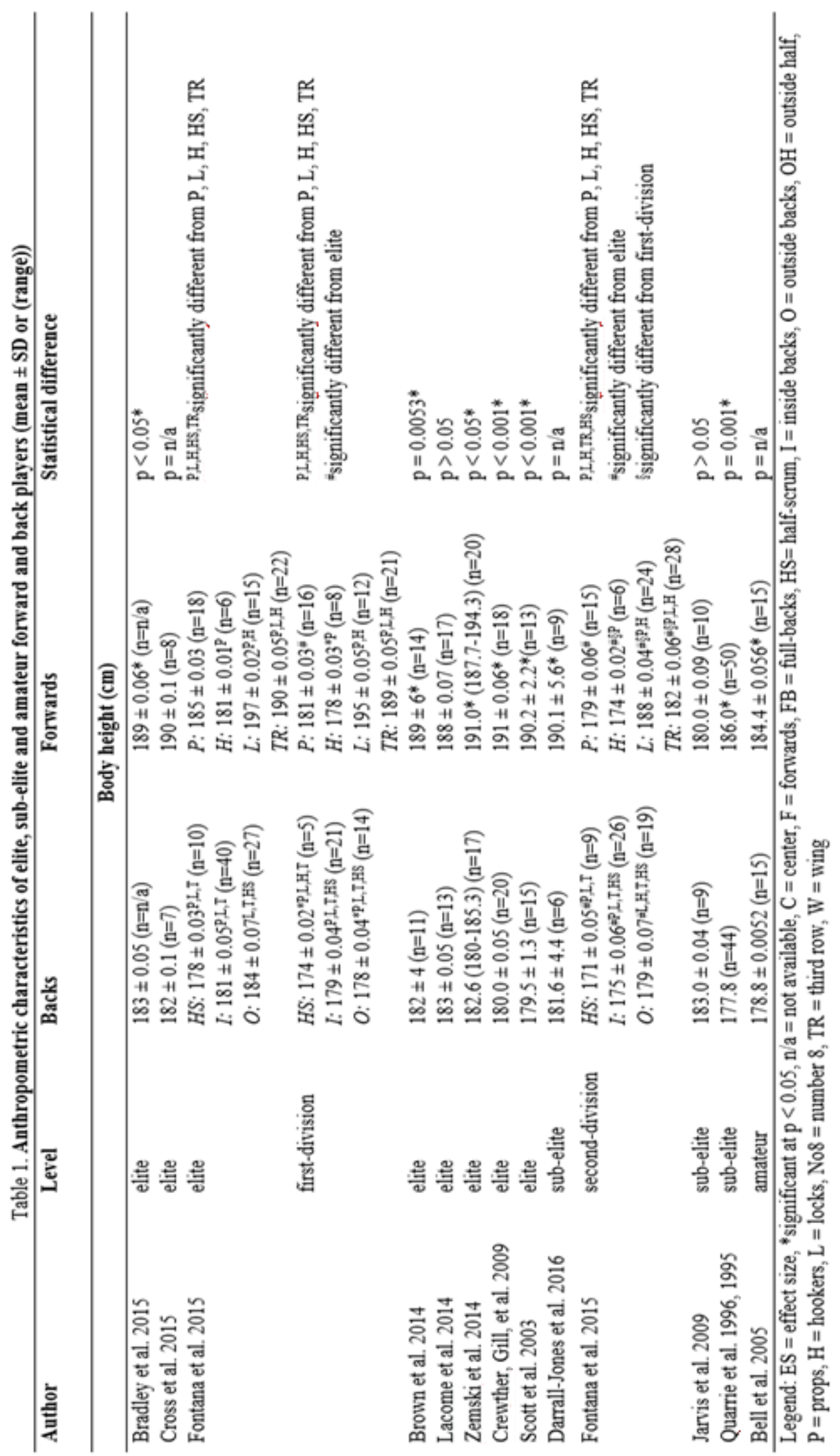




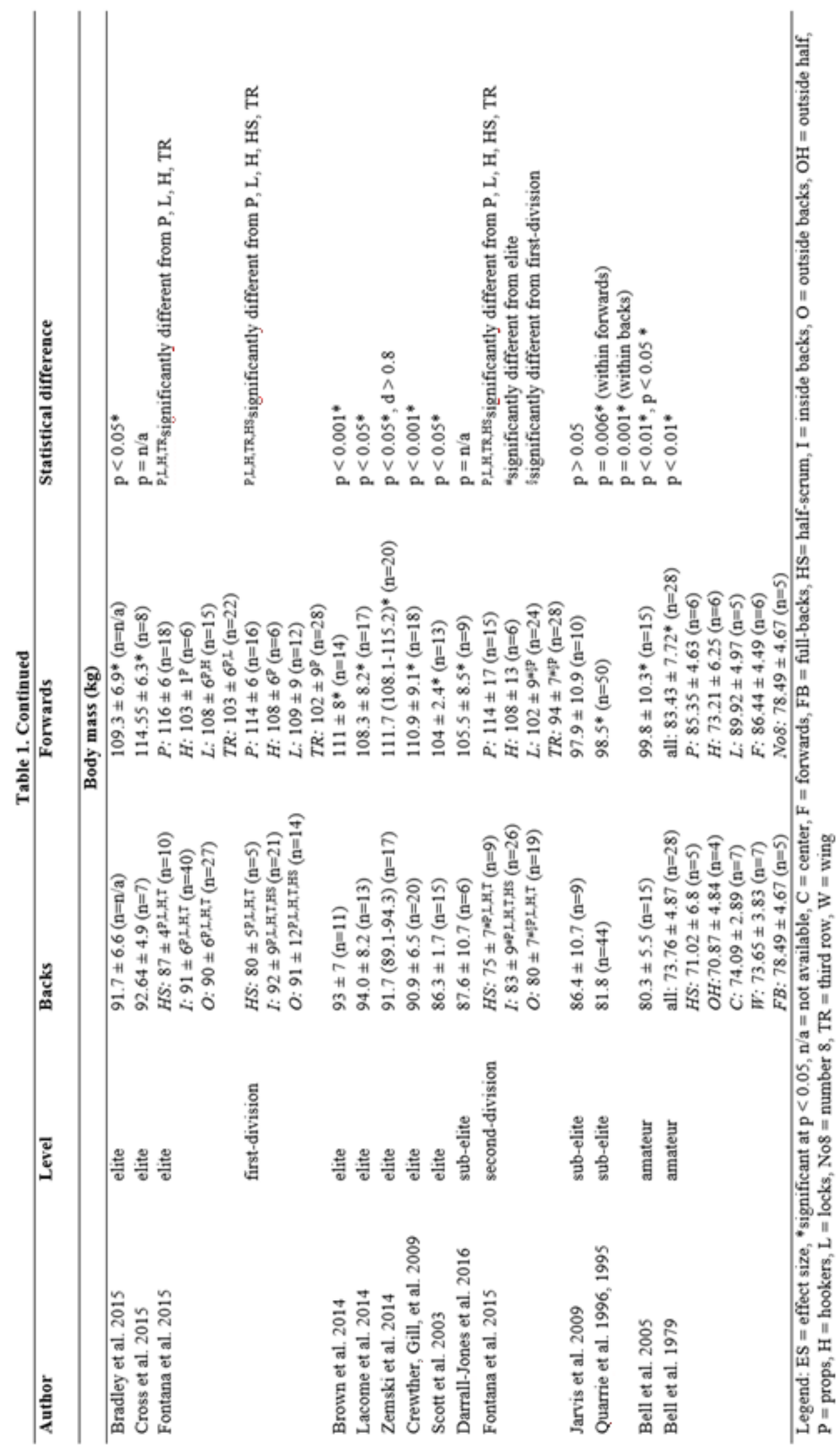




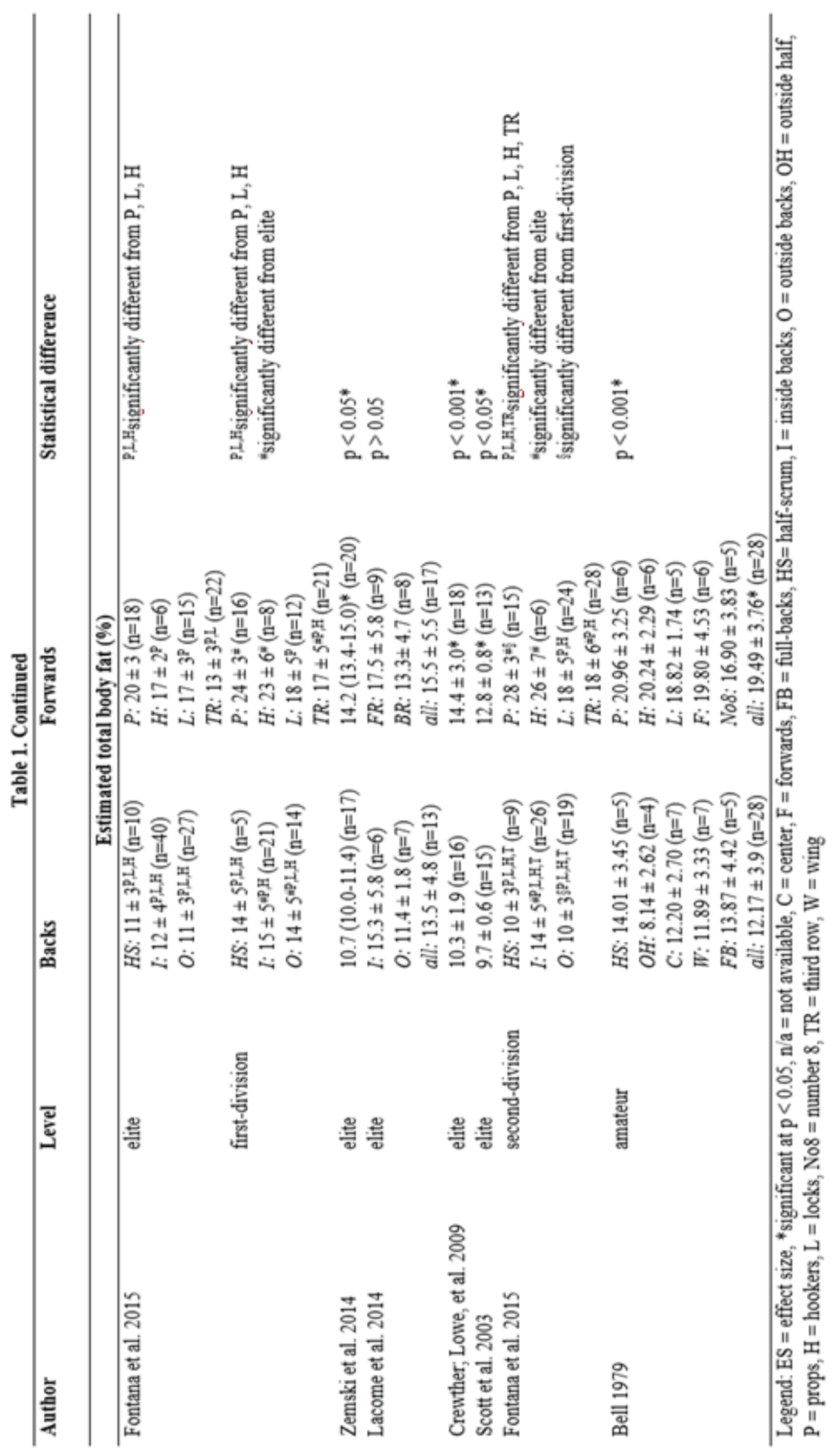




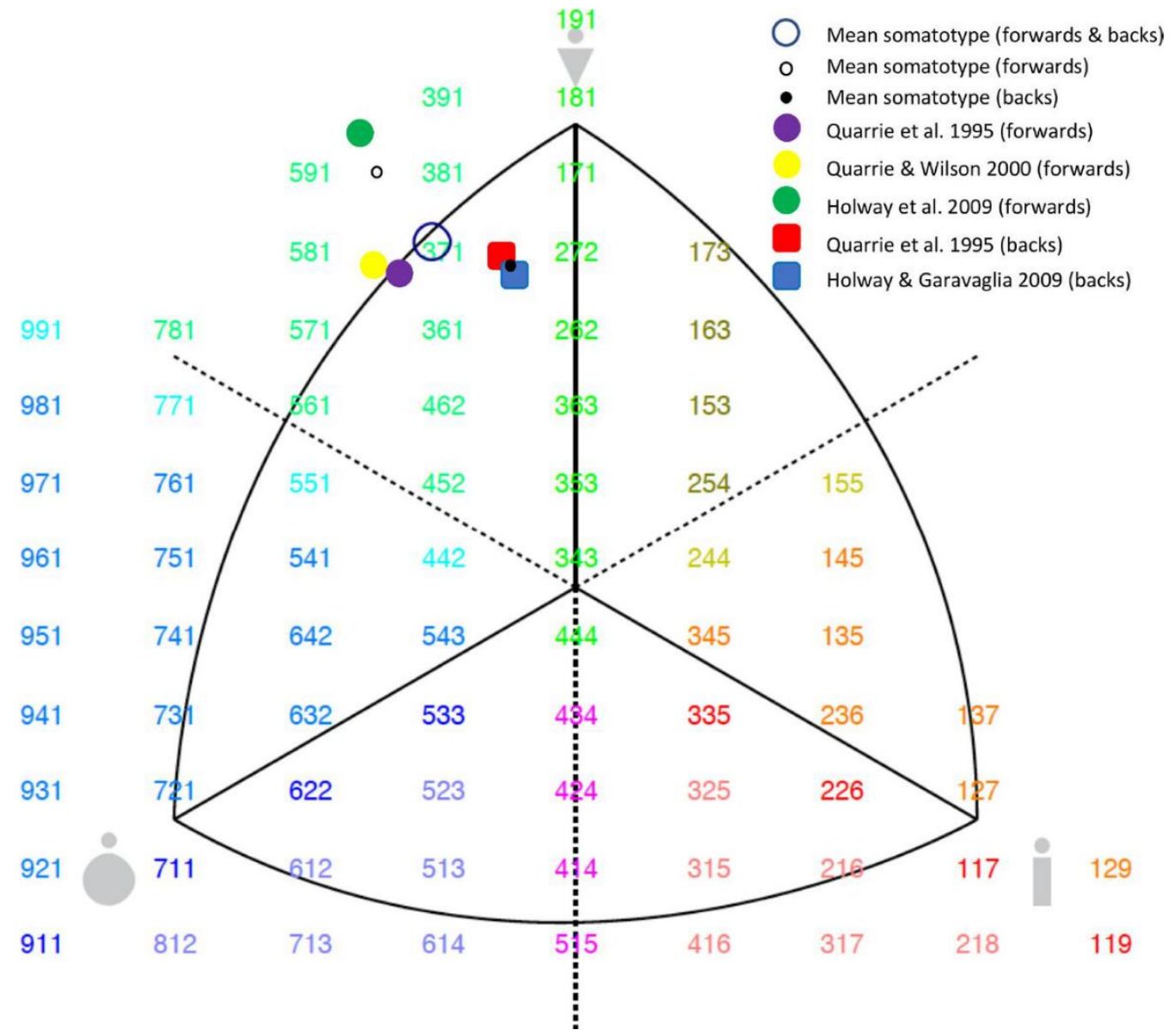

Figure 2. Somatotypes of back and forward players, their means and overall mean.

Table 2. Sprint times for different distances of backs and forwards

\begin{tabular}{|c|c|c|c|c|c|}
\hline Sprint time (s) & Author & Level & Backs & Forwards & Statistical difference \\
\hline $2 \mathrm{~m}$ & Cross et al. 2015 & elite & $0.69 \pm 0.05(\mathrm{n}=7)$ & $0.73 \pm 0.07(\mathrm{n}=8)$ & $\mathrm{p}=\mathrm{n} / \mathrm{a}$ \\
\hline $5 \mathrm{~m}$ & Cross et al. 2015 & elite & $1.23 \pm 0.05(n=7)$ & $1.29 \pm 0.08(\mathrm{n}=8)$ & $\mathrm{p}=\mathrm{n} / \mathrm{a}$ \\
\hline \multirow[t]{4}{*}{$10 \mathrm{~m}$} & Darrall-Jones et al. 2016 & elite & $1.76 \pm 0.12(\mathrm{n}=6)$ & $1.82 \pm 0.10(\mathrm{n}=9)$ & $\mathrm{p}=\mathrm{n} / \mathrm{a}$ \\
\hline & Cross et al. 2015 & elite & $1.95 \pm 0.04(\mathrm{n}=7)$ & $2.04 \pm 0.12(\mathrm{n}=8)$ & $\mathrm{p}=\mathrm{n} / \mathrm{a}$ \\
\hline & Crewther, Lowe, et al. 2009 & elite & $1.73 \pm 0.06(n=11)$ & $1.85 \pm 0.06^{*}(n=13)$ & $\mathrm{p}<0.05^{*}$ \\
\hline & Jarvis et al. 2009 & sub-elite & $1.9 \pm 0.2(\mathrm{n}=9)$ & $2.4 \pm 0.2(\mathrm{n}=10)$ & $p=n / a$ \\
\hline \multirow[t]{3}{*}{$20 \mathrm{~m}$} & Darrall-Jones et al. 2016 & elite & $3.02 \pm 0.15(\mathrm{n}=6)$ & $3.12 \pm 0.11(\mathrm{n}=9)$ & $p=n / a$ \\
\hline & Crewther, Lowe, et al. 2009 & elite & $2.96 \pm 0.09(n=11)$ & $3.16 \pm 0.10^{*}(\mathrm{n}=13)$ & $\mathrm{p}<0.05^{*}$ \\
\hline & Cross et al. 2015 & elite & $3.19 \pm 0.06(n=7)$ & $3.33 \pm 0.15(\mathrm{n}=8)$ & $\mathrm{p}=\mathrm{n} / \mathrm{a}$ \\
\hline \multirow[t]{6}{*}{$30 \mathrm{~m}$} & Cross et al. 2015 & elite & $4.32 \pm 0.09(n=7)$ & $\mathrm{n} / \mathrm{a}$ & $\mathrm{p}=\mathrm{n} / \mathrm{a}$ \\
\hline & Quarrie et al. 1996, 1995 & sub-elite & $I: 4.4(\mathrm{n}=10)$ & $P: 4.6(\mathrm{n}=14)$ & $\mathrm{p}=0.061$ \\
\hline & & & $M: 4.2(\mathrm{n}=13)$ & $H: 4.6(\mathrm{n}=6)$ & (within forwards) \\
\hline & & & $O: 4.2(\mathrm{n}=14)$ & L: $4.5(\mathrm{n}=13)$ & $\mathrm{p}=0.032^{*}$ \\
\hline & & & all: $4.3(\mathrm{n}=37)$ & $L F: 4.4(\mathrm{n}=12)$ & (within backs) \\
\hline & & & & all: $4.5(\mathrm{n}=45)$ & \\
\hline \multirow{2}{*}{$40 \mathrm{~m}$} & Darrall-Jones et al. 2016 & elite & $5.32 \pm 0.22(\mathrm{n}=6)$ & $5.52 \pm 0.17(\mathrm{n}=9)$ & $p=n / a$ \\
\hline & Jarvis et al. 2009 & sub-elite & $5.8 \pm 0.3(n=9)$ & $6.9 \pm 0.4(n=10)$ & $\mathrm{p}=\mathrm{n} / \mathrm{a}$ \\
\hline
\end{tabular}

Legend: * significant at $\mathrm{p}<0.05, \mathrm{n} / \mathrm{a}=$ not available, $\mathrm{I}=$ inside, $\mathrm{M}=$ midfield, $\mathrm{O}=$ outside, $\mathrm{P}=\mathrm{props}, \mathrm{H}=$ hookers, $\mathrm{L}=$ locks, $\mathrm{LF}=$ loose-forwards 
Four different agility tests were utilized in the $\mathrm{n}=2$ retrieved studies, all on sub-elite level players $(27,28)$. Jarvis et al. (2009) reported that the backs were significantly faster than forwards in the T-Test and the Illinois Agility Test ( $\mathrm{p}<$ 0.05). Further, no significant within group differences were found by Quarrie et al. (1996), (backs; $\mathrm{p}=0.623$, forwards; $\mathrm{p}=0.247$ ) (2).

Five studies reported aerobic endurance test results, $\mathrm{n}=1$ in elites (21), $\mathrm{n}=3$ in sub-elites $(27,28,32)$. No significant difference was found for maximal aerobic velocity when assessed by the IPRT $(4.27 \pm 1.1 \mathrm{~m} / \mathrm{s}[\mathrm{n}=13]$ versus $4.3 \pm 0.8$ $\mathrm{m} / \mathrm{s}[\mathrm{n}=17$ ], respectively, $\mathrm{p}>0.05)(21)$. In the sub-elites, the backs completed more $20 \mathrm{~m}$-bouts (No 127.4, $\mathrm{n}=43$ ) during the $20 \mathrm{~m}-\mathrm{MFT}$ than the forwards (No 108.6, $\mathrm{n}=50),(\mathrm{p}=\mathrm{n} / \mathrm{a})(28)$. Within the forwards' group, the hookers performed significantly better than the props $(\mathrm{p}=$ 0.005), within the backs' group the inside backs performed significantly better than the outside backs ( $p=0.001)(2)$. Likewise, the backs reached significantly better $20 \mathrm{~m}$-MFT levels $(10.2 \pm 1.2$ $[\mathrm{n}=9]$ compared to the forwards $(8.1 \pm 1.6[\mathrm{n}=$ $10], \mathrm{p}<0.05,(27)$. The same trend was found for the YYIRT level 1 but not for the 30-15 IFT between the units (29).

For lower body strength significantly higher one repetition maximums (1RM) compared to the backs' in squats $(22,30)$ were reported for elites ( $\mathrm{p}<0.05$ ) (30). After body mass correction using allometric scaling (1RM $\left.\mathrm{kg}^{0.67}\right)$, the difference became non-significant $(22,30)$.

Crewther et al. (2012) reported no significant difference in CMJ PPO performance between inside and outside backs, and loose and tightforwards $(\mathrm{p}=0.272)(31)$. After mass correction, the inside and outside backs jumped both significantly higher than the tight-forwards $(\mathrm{p}<$ 0.05) (31). After allometric scaling, only the outside backs reached significantly higher values than the tight-forwards $(\mathrm{p}=0.014)(31)$. In an earlier study, they found significantly higher 70$\mathrm{kg}$ SJ PPO values in forwards $(\mathrm{p}<0.05)$. After ratio scaling, the backs still reached significantly higher values and after allometric scaling, no significant difference remained (forwards: 246.4 $\left.\pm 26.2 \mathrm{~W} \cdot \mathrm{kg}^{0.67},[\mathrm{n}=14]\right)$ versus backs: $247.6 \pm$ $\left.26.2 \mathrm{~W} \cdot \mathrm{kg}^{0.67},[\mathrm{n}=11]\right),(\mathrm{p}<0.05)(30)$. Quarrie and Wilson (2000) performed a standing and arm reach up $\mathrm{CMJ}$ in elite forwards. Their results showed that the loose-forwards jumped significantly higher than the props $(\mathrm{p}<$ $0.001)(14)$. The mean VJ height of sub-elite backs was reported as $63.2 \mathrm{~cm}(\mathrm{n}=44)$ and for the forwards as $59.7 \mathrm{~cm}(\mathrm{n}=50),(\mathrm{p}=\mathrm{n} / \mathrm{a})(28)$, within the backs $(\mathrm{p}=0.290)$ and forwards $(\mathrm{p}=$ $0.094)$ no significant difference existed (2).

Bench press performance for upper body strength showed significantly higher values for the elite forwards than the backs $(\mathrm{p}<0.001)(30)$. Crewther, Gill, et al. (2009) mentioned higher values at $\mathrm{p} \leq 0.05$ for forwards, which still remained after ratio scaling but disappeared after allometric scaling (22). In Crewther, Lowe, et al. (2009), even after allometric scaling the difference stayed significant $(\mathrm{p}<0.05)$ (30). Quarrie et al. (1995) measured the maximal number of push-ups completed during a given set up with a cadence of 50 beats per minutes. The backs performed significantly more push-ups $(\mathrm{n}=$ 32.3 repetitions) than the forwards $(\mathrm{n}=25.6$ repetitions), $(\mathrm{p}=0.001)$ (28). No positional differences within the units could be found (forwards; $p=0.246$, backs; $p=0.784$ ) (2).

For upper body power production $50-\mathrm{kg}$ bench throw PPO in elite players was measured $(22,30)$. In one study the mean and PPO results differed significantly between the forwards and backs ( $\mathrm{p}<$ 0.05 ) and became non-significant after allometric scaling (30). In the other study the PPO values were different before and after ratio scaling at a significance level of $\mathrm{p} \leq 0.05$, but not after allometric scaling (22).

\section{DISCUSSION}

\section{Anthropometry}

and Somatotype. Regardless of playing level, the forwards were taller and heavier than the backs. The sub-elites were generally shorter than the elite players (28). This finding is in line with the fact that usually tall players become elite Rugby athletes. Since teams with the tallest forwards win a greater number of matches, this anthropometric advantage has great importance (12). As height cannot be influenced by training, it is uniquely a matter of directional selection (10). Over a time period of 20 years (1988 to 2008), the average height of an elite back increased by $5.4 \mathrm{~cm}$, and of the elite forward by $2.9 \mathrm{~cm}$ (10). From the time period 1905 to 1974 to the years 1975 to 1999 , the average body mass of forwards increased by $11 \mathrm{~kg}$, whereas the backs 
only gained $4.7 \mathrm{~kg}$ (12). Interestingly, from 1988 to 2008 , the backs became even heavier by about $12 \mathrm{~kg}$ (10). Consequently, for the time period between the years 1905 to 1999 Olds (2001) described a significant reduction in endomorphism and mesomorphism in high-level Rugby union backs and forwards and of ectomorphism in forwards only (12). Those changes in anthropometric parameters and somatotypes may be associated with and have developed due to changing match demands that followed rule changes $(7,8)$. Playing situations requiring an increase in force augmented, therefore body mass became essential to sustain the forces. Evidence that teams with the heaviest forwards and backs won more matches than their lighter opponents support this evolution $(9,12)$.

Physical Performance. Analyzing the locomotive parameters during match play, data on total distance covered and locomotive variables were only available for elites with only small sample sizes, maybe since the used GPS-tracking systems are costly $(3,24,25)$. The backs covered less standing distance, more distance in walking, moving at high-intensities and sprinting than the forwards. Both positions covered equal distances jogging $(3,24)$ and with medium-intensity running (21). Moreover, one study reported greater jogging distances for forwards than backs (26). However, according to Reardon et al. (2015) the use of absolute speed thresholds, as used in the retrieved studies, rather than individual playing position speed zones may lead to an overestimation of high-speed running in backs and an underestimation in forwards (41). Supporting this assumption, both units experience an equal reduction in the relative distance covered at high-intensities in the second match half, indicating fatigue $(44,45)$. On the assumption that sub-elites and amateurs have fewer, less intense training sessions we conclude them to have a lower physical capacity and therefore a smaller amount of total distance covered during match with less minutes at high-intensity speeds.

Sprint results revealed that backs were faster than forwards across all studies and all sprint distances, with heavier, taller and slower forwards (except Jarvis et al. [2009]) than backs. Within the backs, the heaviest and shortest were the fastest (30). These results suggest that over a short sprint distance, leg power has more importance than ectomorphism within the backs. Nevertheless, the time differences for all sprint distances were sometimes surprisingly small, revealing, that both units require and are trained for the sprinting demands during match play $(2,27,30,32,35)$.

In terms of sprint velocities, the results of elite players uniformly showed that the taller and heavier forwards reached higher sprint velocities in the $10 \mathrm{~m}$ and $20 \mathrm{~m}$ distance, whereas the backs performed better in $30 \mathrm{~m}$ and $60 \mathrm{~m}$ distances. These findings reflect power components necessary for short distances and endurance linked with ectomorphic somatotype required for maintaining speed over longer distances. Analyzing sprint momentum over 10 and $30 \mathrm{~m}$, large body size (height and mass) is advantageous for gaining better results. For training purposes, following the findings of Barr et al. (2014), the optimal training adaptation time sequence in developing sprint momentum and speed through enhanced muscular hypertrophy and power is likely in the late teens to early twenties rather than later (46). Considering these results, amateur players could improve their sprint performance by enhancing their ectomorphic component and by gaining body mass through muscle mass increase.

The shorter and lighter backs performed better in the agility tests than the taller and heavier forwards. Not surprisingly, the backs covered a greater distance than the forwards in the aerobic tests. The result highlights the negative effect of high body mass on aerobic running test performance, therefore the calculated $\mathrm{VO}_{2 \max }$, is underestimated in heavier players. The YYIRT was mentioned to be of sufficient sensitivity to discover training-induced changes in repeated high-intensity exercise similar to that occurring in Rugby union (47), in contrast to absolute values.

In terms of strength parameters, elite and subelite forwards reached higher 1RMs in lower and upper limb strength tests than backs after ratio scaling. However, after allometric scaling (48), the significance did not remain for lower limb strength and the results for upper limb strength were contradictory. Amateur backs were the shortest and lightest players within the backs, with the lowest strength values. Consequently, elite backs performed best, but it was the oldest, not the heaviest back, who performed best on the $1 \mathrm{RM}$ bench press. Push-up testing for upper body 
power showed that sub-elite backs who were shorter and lighter reached a greater number reflecting the influence of supported or unsupported body mass in testing situations.

After ratio scaling, the elite backs reached higher force production in the CMJ than the forwards, however, after allometric scaling, the difference was no longer significant, highlighting the bias of body mass. The literature discussed ratio scaling for functional test performance, allometric scaling for force-generated activities (49), tests with additional external load or those at slow movement speeds (22). For upper body force production, elite backs who were shorter and lighter produced a lower PPO during $50-\mathrm{kg}$ bench throw as the older, taller and heavier forwards $(22,30)$. Hence, with respect to force parameters, a higher body mass consisting of a high percentage of muscle mass, increases 1RM and jump performance.

\section{CONCLUSION}

Across all playing levels of Tier 1 nations, the forwards were taller and heavier than the back players. Heavy body mass positively affects sprint momentum, short sprints, and sustaining force in demanding situations. Consequently, as body mass simultaneously favors speed and strength performance and body height positively affects power, results should be carefully interpreted by means of ratio or allometric scaling when comparing forwards and backs. Concerning the locomotive parameters, the number of repeated high-intensity runs during match may not account more for the backs since literature criticizes an overestimation for the backs, respectively an underestimation for the forwards. For the compared parameters, the general view is "the higher the level, the higher the values", emphasizing the importance of training volume and match intensity as important components in developing physical characteristics.

The findings of this review should be considered critically as the power of the results is limited due to the heterogeneity of the reported outcome parameters and its descriptive study design. Although only studies on Tier 1 nations were discussed, the subdivision into amateur, sub- elite and elite level remains vague since categorization varies within each country. Therefore, the grouping of the included studies used in this review may be questioned. Upcoming studies would profit from performing powerful statistics in terms of a meta-analysis, from rating the studies' methodological quality to ensure high-level research and to clearly classify the players using international standards. This review shows the differences in anthropometric and physical performance parameters between Rugby union forward and back players of different levels of Tier 1 nations and highlights the need to follow Rugby union players in terms of body composition to ensure a Rugby specific somatotype according to playing position.

\section{APPLICABLE REMARKS}

- Regarding anthropometric properties, Rugby Union forwards are significantly taller than backs at the elite level. The lower the classification level, the smaller the height difference between forwards and backs.

- Across all levels, the forwards are significantly heavier than the backs reflecting the demands of each playing position.

- As the level increases, so does the speed of the backs in sprints.

- Regardless of playing level, the backs performed significantly better in sprints and attained higher jump values than the forwards.

- In contrast, forwards achieved higher 1RM results in lower and upper body strength assessments.

\section{ACKNOWLEDGMENT}

The authors like to thank the "Thim van der Laan" foundation, Landquart, Switzerland, for the financial support. 


\section{REFERENCES}

1. Nicholas CW. Anthropometric and Physiological Characteristics of Rugby Union Football Players. Sport Med. 1997;23(6):375-96.

2. Quarrie KL, Handcock P, Toomey MJ, Waller AE. The New Zealand rugby injury and performance pro ject . IV . Anthropometric and physical performance comparisons between positional categories of senior A rugby players. Br J Sports Med. 1996;30:53-6.

3. Cunniffe B, Proctor W, Baker JS, Davies B. An Evaluation of the Physiological Demands of Elite Rugby Union using Global Positioning System Tracking Software. J Strength Cond Res. 2009;23(4):1195-203.

4. van Rooyen M, Rock K, Prim SK, Lambert MI. The quantification of contacts with impact during professional rugby matches. Int J Perform Anal Sport [Internet]. 2008;8(1):113-26. Available from: papers://cdf6ea96-27e8-40e2a222-

a38262792b20/Paper/p312\%5Cnhttp://www.ingentaconnect.com/content/uwic/ujpa/2008/00000008/00000001/ar t00012?crawler=true

5. Hohenauer E, Rucker AM, Clarys P, Küng U, Stoop R, Clijsen R. Anthropometric and performance characteristics of the German rugy union $7 \mathrm{~s}$ team.

6. Vaz L, Morais T, Rocha H, James N. Fitness profiles of elite portuguese rugby union players. J Hum Kinet. 2014;41(June):235-44.

7. Owen SM, Venter RE, du Toit S, Kraak WJ. Acceleratory match-play demands of a Super Rugby team over a competitive season. J Sports Sci. 2015;414(July):1-9.

8. Quarrie KL, Hopkins WG. Changes in player characteristics and match activities in Bledisloe Cup rugby union from 1972 to 2004. J Sport Sci. 2007;25(8):895-903.

9. Sedeaud A, Marc A, Schipman J, Taffl M, Hager J, Toussaint J. How they won Rugby World Cup through height , mass and collective experience. Br J Sports Med. 2012;46:580-4.

10. Sedeaud A, Vidalin H, Tafflet M, Marc A, Toussaint J-F. Rugby morphologies: "bigger and taller", reflects an early directional selection. J Sport Med Phys Fit. 2013;53(November 2016):185-91.

11. Lombard WP, Durandt JJ, Masimla H, Green M, Lambert MI. Changes in Body Size and Physical Characteristics of South African Under-20 Rugby Union Players Over a 13-Year Period. J Strength Cond Res. 2015;29(4):980-8.

12. Olds T. The evolution of physique in male rugby union players in the twentieth century. J Sports Sci. 2001;19(4):253-62.

13. Smart D, Hopkins WG, Quarrie KL, Gill N. The relationship between physical fitness and game behaviours in rugby union players. Eur J Sport Sci. Taylor \& Francis; 2011;14(December):1-10.

14. Quarrie KL, Wilson BD. Force production in the rugby union scrum. J Sports Sci. 2000;18(January 2015):237-46.

15. Fontana FY, Colosio AL, Da Lozzo G, Pogliaghi S. Player's success prediction in rugby union: From youth performance to senior level placing. J Sci Med Sport. Sports Medicine Australia; 2016;

16. Fontana FY, Colosio A, Roia GF De, Lozzo G Da, Pogliaghi S. Anthropometrics of Italian Senior Male Rugby Union Players : From Elite to Second Division. Interational J Sport Physiol Perform. 2015;10:674-80.

17. Liberati A, Altman DG, Tetzlaff J, Mulrow C, Gøtzsche PC, Ioannidis JPA, et al. The PRISMA statement for reporting systematic reviews and meta-analyses of studies that evaluate health care interventions: explanation and elaboration. J Clin Epidemiol. 2009;62(10):e1-34.

18. Bell W. Body composition of rugby union football players. Br J Sports Med. 1979;13(1):19-23.

19. Zemski AJ, Slater GJ, Broad EM. Body composition characteristics of elite Australian rugby union athletes according to playing position and ethnicity. J Sports Sci. 2015;33(9):970-8.

20. Bell W, Evans WD, Cobner DM, Eston RG. Regional placement of bone mineral mass, fat mass, and lean soft tissue mass in young adult rugby union players. Ergonomics. 2005;48(11-14):1462-72.

21. Lacome M, Piscione J, Hager J-P, Bourdin M. A new approach to quantifying physical demand in rugby union. J Sports Sci. 2014;32(3):290-300.

22. Crewther BT, Gill N, Weatherby RP, Lowe T. A comparison of ratio and allometric scaling methods for normalizing power and strength in elite rugby union players. J Sports Sci. 2009;27(14):1575-80.

23. Scott AC, Roe N, Coats AJS, Piepoli MF. A erobic exercise physiology in a professional rugby union team. Int J Cardiol. 2003;87(2):173-7.

24. Roberts SP, Trewartha G, Higgitt RJ, El-Abd J, Stokes KA. The physical demands of elite English rugby union. J Sports Sci. 2008;26(8):825-33.

25. McLaren SJ, Weston M, Smith A, Cramb R, Portas MD. Variability of physical performance and player match loads in professional rugby union. J Sci Med Sport. 2016;19(6):493-7.

26. Deutsch MU, Kearney GA, Rehrer NJ. Time-motion analysis of professional rugby union players during match- 
play. J Sports Sci. 2007;25(4):461-72.

27. Jarvis S, Sullivan LEEO, Davies B. Interrelationships between measured running intensities and agility performance in subelite rugby union players. Res Sport Med. 2009;17(July):217-30.

28. Quarrie KL, Handcock P, Wallert AE, Chalmers DJ, Toomeyl MJ, Wilsont BD. The new zealand rugby injury and performance project. III. Anthropometric and physical performance charcteristics of players. Br J Sports Med. 1995;29(4):263-70.

29. Darrall-Jones JD, Jones B, Till K. Anthropometric, Sprint, and High-Intensity Running Profiles of English Academy Rugby Union Players by Position. J Strength Cond Res. 2015;30(5):1348-58.

30. Crewther BT, Lowe T, Weatherby RP, Gill N, Keogh J. Neuromuscular performance of elite rugby union players and relationship with salivary hormones. J Strength Cond Res. 2009;23(7):2046-53.

31. Crewther BT, Kilduff LP, Cook CJ, Cunningham DJ, Bunce PJ, Bracken RM, et al. Scaling strength and power for body mass differences in rugby union players. J Sport Med Phys Fit. 2012;52:27-32.

32. Darrall-Jones JD, Jones B, Till K. Anthropometric and physical profiles of english academy rugby union players. J Strength Cond Res. 2015;29(8):2086-96.

33. Brown SR, Brughelli M, Griffiths PC, Cronin JB. Lower-Extremity Isokinetic Strength Profiling in Professional Rugby League: Discovery Service. Int J Sports Physiol Perform. 2014;(9):358-61.

34. Bradley WJ, Cavanagh BP, Douglas W, Donovan TF, Morton JP, Close GL. Quantification of training load, energy intake, and physiological adaptations during a rugby preseason: a case study from a elite eurpoean rugby union squat. J Strength Cond Res. 2015;29(2):534-44.

35. Cross MR, Brughelli M, Brown SR, Samozino P, Gill ND, Cronin JB, et al. Mechanical Properties of Sprinting in Elite Rugby Union and Rugby League. Interational J Sport Physiol Perform. 2015;10:695-702.

36. Holway FE, Garavaglia R. Kinanthropometry of Group I rugby players in Buenos Aires, Argentina. J Sports Sci. 2009;27(September):1211-20.

37. Swaby R, Jones PA, Comfort P. Relationship between Maximum Aerobic Speed Performance and Distance Covered in Rugby Union Games. J Strength Cond Res. 2016;1-16.

38. Cahill N, Lamb K, Worsfold P, Headey R, Murray S. The movement characteristics of English Premiership rugby union players. J Sports Sci. 2013;31(3):1-9.

39. Roberts SP, Stokes KA, Weston L, Trewartha G. The Bath University Rugby Shuttle Test (BURST): A pilot study. Int J Sports Physiol Perform. 2010;5(1):64-74.

40. Jones MR, West DJ, Harrington BJ, Cook CJ, Bracken RM, Shearer DA, et al. Match play performance characteristics that predict post-match creatine kinase responses in professional rugby union players. BMC Sport Sci Med Rehabil. 2014;6(38):1-7.

41. Reardon C, Tobin DP, Delahunt E. Application of individualized speed thresholds to interpret position specific running demands in elite professional rugby union: A GPS Study. PLoS One. 2015;10(7):1-12.

42. Jones B, Emmonds S, Hind K, Nicholson G, Rutherford Z, Till K. Physical qualities of international female rugby league players by playing position. J Strength Cond Res. 2015;30(5):1333-40.

43. Duthie GM, Pyne DB, Marsh DJ, Hooper SL. Sprint patterns in rugby union players during competition. J Strength Cond Res. 2006;20(1):208-14.

44. Tee J, Lambert M, Coopoo Y. Impact of fatigue on positional movements during professional Rugby Union match play. Int J Sports Physiol Perform. 2016;

45. Lacome M, Piscione J, Hager JP, Carling C. Analysis of running and technical performance in substitute players in international male rugby union competition. Int J Sports Physiol Perform. 2016;11(6):783-92.

46. Barr MJ, Sheppard JM, Gabbett TJ, Newton RU. Long-Term Training-Induced Changes in Sprinting Speed and Sprint Momentum in Elite Rugby Union Players. J Strength Cond Res. 2014;28(10):2724-31.

47. Austin D, Gabbett TJ, Jenkins DG. Reliability and Sensitivity of a Repeated High-Intensity Exercise Performance Test for Rugby League and Rugby Union. J Strength Cond Res. 2013;27(4):1128-35.

48. Jaric S, Mirkov D, Markovic G. Normalizing physical performance tests for body size: a proposal for standardization. J Strength Cond Res. 2005;19(2):467-74.

49. Crewther BT, McGuigan MR, Gill ND. The Ratio and Allometric Scaling of Speed, Power, and Strength in Elite Male Rugby Union Players. J Strength Cond Res. 2011;25(7):1968-75. 